\title{
Dislexia em perspectiva: Contribuições da psicopedagogia e da Psicologia
}

\author{
Eliabe Bezerra de oliveira Silva Amorim ${ }^{1}$; Gislene Farias de Oliveira ${ }^{2}$
}

\begin{abstract}
Resumo: O presente artigo tem como título "Dislexia em perspectiva: contribuições da psicopedagogia e da psicologia" e trata da "dislexia do escolar" sob os prismas da psicopedagogia espanhola e argentina, e da psicologia do desenvolvimento, educacional e escolar. O intuito deste trabalho não é dissertar a respeito de todos os tipos de dislexia escolar encontrados por essas áreas de estudo, mas evidenciar aos profissionais da educação formal os principais sinais de dificuldades de leitura e escrita presentes nos sujeitos em processo de escolarização. Dentro dessa proposta de revisão integrativa, consideram-se os aspectos cognitivo, pedagógico e social interferentes no processo de ensino-aprendizagem. Sob o método da pesquisa bibliográfica com cruzamento de fontes e interpretação de conteúdo, e da observação direta das relações familiares, das rotinas escolares e das práticas pedagógicas em escolas municipais de Fortaleza - Ceará, foi possível estabelecer relações multicausais para a construção dos argumentos, no sentido de renovar a discussão sobre o tema, possibilitando novos esclarecimentos e ultrapassando a reprodução da nomenclatura existente sobre dificuldades da lectoescrita. Os resultados demonstraram uma relação entre cognição social e postura político-pedagógica da escola e do professor, e implicações de tais relações no sujeito aprendente. Estas precisam ser consideradas quando os propósitos maiores são superar o paradigma homogeneizador da escola brasileira, realçar as potencialidades dos sujeitos e alcançar a qualidade da educação.
\end{abstract}

Palavras-chave: Dislexia. Aprendizagem. Ensino. Escola. Leitura. Escrita.

\section{Dyslexia in perspective: Contributions of Educational Psychology and Psychology}

\begin{abstract}
This article is entitled "Dyslexia in perspective: contributions of educational psychology and psychology" and deals with "dyslexia of school" under the prism of Spanish and Argentine educational psychology, and developmental psychology, educational and school. The purpose of this work is not expound in respect of all kinds of school dyslexia found in these areas of study, but to highlight the professionals of formal education the main signs reading and writing difficulties present in the subject in the schooling process. Within this proposal of an integrative review, we consider the cognitive, educational and social interfering in the teaching-learning process. From the method of literature with intersecting sources and interpretation of content, and direct observation of family relations, school routines and teaching practices in public schools in Fortaleza Ceará, was possible to establish multi-causal relationships for the construction of the arguments in to renew the discussion on the topic, providing new insights and surpassing the reproduction of existing nomenclature of difficulties lectoescrita. The results showed a relationship between social cognition and political-pedagogical approach of the school and the teacher, and implications of such relations in the individual learner. These need to be considered when the major purposes are to overcome the homogenizing paradigm of Brazilian school, highlight the potential of the individuals and achieve quality education.
\end{abstract}

Keywords: Dyslexia. Learning. Teaching. School. Reading. Writing.

\footnotetext{
${ }^{1}$ Mestrando em Educação pela Anne Sullivan University. Professor de Língua Portuguesa da rede pública de ensino do Estado do Ceará. Especialista em Psicopedagogia Clínica e Institucional. Músico. E-mail: prof_eliabe@ yahoo.com.br;

${ }^{2}$ Psicóloga. Doutora em Psicologia social pela universidade Federal da Paraíba. Pós-Doutorado em Ciências da Saúde pela Faculdade de Medicina do ABC, São Paulo. E-mail: gislenefarias@gmail.com.
} 
Id on Line Revista Multidisciplinar e de Psicologia

Id on Line Multidisciplinary Journal and Psycology

\section{Introdução}

Durante quatro décadas o capitalismo percorreu um processo de reestruturação e hoje atingiu o nível de complexidade que uns esperavam e outros temiam. As relações entre o capital e as pessoas se tornaram mais complexas e aumentaram ainda mais a discrepância entre o poder aquisitivo dos ricos e a condição dos pobres. As desigualdades contaminaram também outros âmbitos das relações humanas: a religião, a cultura e a educação.

Não obstante, o quadro caótico do capitalismo reflete na escola e nas crianças uma gama de problemas cujas nuances o professor, embora mais preparado do que há 30 anos, não consegue entrever nem solucionar. A escola e o professor ainda não conseguem promover uma educação de qualidade suficientemente eficaz a fim de minimizar as desigualdades referentes ao acesso democrático à cultura e ao conhecimento e, consequentemente, evitar o aparecimento ou o agravamento das dificuldades de aprendizagem, muitas delas relacionadas à conjuntura socioeconômica e às características da educação homogeneizadora (OLIVEIRA, 2010).

Nessa conjuntura, os profissionais da educação formal, com apoio da família, têm grande desafio frente às dificuldades de aprendizagem de leitura e escrita mais recorrentes em âmbito escolar: a dislexia, a disortografia e a disgrafia. Reitera-se que não há intenção apressada em configurar a etiologia dessas dificuldades nem criar rótulos diretos para elas, mas reunir conhecimentos em direção ao quadro etiológico mais seguro.

A fim de fazer jus ao desafio, este artigo apresenta a revisão integrativa das contribuições das ciências e áreas do conhecimento aplicadas à educação escolar, em destaque a Psicopedagogia, a Psicologia e a Linguística, além de aproximações mais estreitas entre Psicologia da Educação e do Desenvolvimento, Psicolinguística e Psicopedagogia. Há um construto teórico-prático dessas áreas que necessitam de reinterpretação e aplicação metodológica.

O trabalho consiste numa síntese de conhecimentos específicos a respeito de dificuldades de leitura e escrita. Também não há a intenção aqui de repassar, sugerir ou analisar procedimentos e técnicas restritas ao trabalho clínico do psicólogo ou do psicopedagogo, nem fazer um conglomerado eclético e caótico de informações, mas enriquecer o debate sobre os problemas da lecto-escritura mediante relação dialógica entre ciências que fazem fronteira nesse tema de investigação. Portanto, o trabalho adota uma 
Id on Line Revista Multidisciplinar e de Psicologia

Id on Line Multidisciplinary Journal and Psycology

postura multifocal e interessa aos professores e outros profissionais que estão envolvidos na educação escolar, infantil e fundamental.

Em atenção à progressão temática, o trabalho está organizado em partes. A primeira é a apresentação do macrocontexto e do microcontexto do problema, caracterizando a problematização; a segunda traz o breve histórico do conceito de dislexia e a terceira sintetiza os resultados da pesquisa. Por fim, a conclusão põe os encaminhamentos e as perspectivas para novas discussões e pesquisas.

\section{Problematização}

As formas de vida da sociedade contemporânea requerem dos pesquisadores e profissionais da educação formal e informal mudança de enfoque e abordagem da realidade. A intensidade dos processos sociais e a dinamicidade da articulação e divulgação social do conhecimento estão intrinsecamente ligadas às diversas tecnologias de informação e comunicação, as quais compõem o conjunto de estímulos sensoriais que a criança desde cedo começa a receber.

Essa realidade preconiza novas formas de inteligência e relacionamento, potencializando a expressão das idiossincrasias pelos sujeitos aprendentes. Não obstante, as particularidades de pensamento e ação se distanciam cada vez mais das propostas pedagógicas homogeneizadoras que predominam nos sistemas de ensino particulares e públicos de países capitalistas.

Ajuriaguerra (1984, p.72-80) explica que estímulos precários na primeira infância, problemas pedagógicos em séries iniciais e fatores afetivo-emocionais na escola e na família estão entre as principais causas dos problemas no desenvolvimento psicossocial, cognitivo e de transtornos na aprendizagem. Considera-se à parte as dificuldades de aprendizagem decorrentes de lesões ou paralisias cerebrais, que merecem maior atenção médica.

A fim de que a abordagem do problema tenha o rigor científico necessário para a consecução do presente trabalho, é de suma relevância apresentar uma definição bastante consensual sobre o que se entende por dificuldades de aprendizagem (Learning Desabilities LD), sobretudo nos EUA, em cuja história se encontra o cerne dos estudos históricos do assunto (assim como a França foi referência e, hoje, a Argentina com a psicopedagogia). 
Id on Line Revista Multidisciplinar e de Psicoloqia

Id on Line Multidisciplinary Journal and Psycology

Trata-se da definição proposta pelo National Joint Committee on Learning Desabilities (NJCLD) de 1988, apresentada por Garcia (1998, p.31 e 32):

\begin{abstract}
Dificuldade de Aprendizagem (DA) é um termo geral que se refere a um grupo heterogêneo de transtornos que se manifestam por dificuldades significativas na aquisição e uso da escuta, fala, leitura, escrita, raciocínio ou habilidades matemáticas. Esses transtornos são intrínsecos ao indivíduo, supondo-se devido à disfunção do sistema nervoso central, e podem ocorrer ao longo do ciclo vital. Podem existir, junto com as dificuldades de aprendizagem, problemas nas condutas de autorregulação, percepção social e interação social, mas não constituem, por si próprias, uma dificuldade de aprendizagem. Ainda que as dificuldades de aprendizagem possam ocorrer concomitantemente com outras condições incapacitantes (por exemplo, deficiência sensorial, retardamento mental, transtornos emocionais graves) ou com influências extrínsecas (tais como as diferenças culturais, instrução inapropriada ou insuficiente), não são os resultados dessas condições ou influências.
\end{abstract}

É necessário, antes da análise, fazer a distinção entre palavras do mesmo universo semântico da psicopedagogia e da psicologia escolar. São elas: problema, dificuldade, transtorno, deficiência, distúrbio e desvio. Consensualmente, problema e dificuldade são considerados sinônimos e significam impedimento, obstáculo ${ }^{1}$, estorvo ou complicação para a aprendizagem.

A deficiência é o déficit, a ausência de algo essencial que acarreta insuficiência ou precariedade na aprendizagem. Não se confunde com distúrbio, sinônimo de transtorno que significa qualquer perturbação ou interrupção da normalidade, prejudicando a aprendizagem.

O consenso entre alguns estudiosos do assunto não impede a existência de dúvidas quanto à delimitação clara dos termos supramencionados, os quais se fundem e se confundem muitas vezes, haja vista os sintomas diversos e coexistentes em muitos casos de aprendentes com DA. Há também autores que se dedicam ao assunto usam os termos indiscriminadamente.

Não obstante, a própria explanação das DA específicas para este trabalho - dislexia, disgrafia e disortografia - delimitará a concepção adotada e eliminará possíveis dúvidas.

Garcia (1998, p. 173) define as dificuldades de aprendizagem da leitura ou dislexia pelo déficit no desenvolvimento do reconhecimento e compreensão de textos escritos. Segundo ele, "não se pode causalizar o problema com a deficiência mental, a inadequada ou escassa escolarização, o déficit visual ou auditivo, nem o problema neurológico".

\footnotetext{
${ }^{1}$ Handicapp: termo usado nos EUA. 
As supostas ou evidentes alterações no sistema nervoso central não descartam as críticas feitas ao enfoque neuropsicológico, principalmente no que diz respeito à existência de relação causal entre alteração orgânica e dificuldades de aprendizagem de leitura, visto que crianças com tais problemas não apresentam dificuldades de aprendizagem e vice-versa. No entanto, ainda há grupos de pesquisa que defendem a hereditariedade de problemas ou transtornos cognitivos.

A psicopedagogia argentina e a brasileira não seguem ortodoxamente a definição do NJCLD proposta por Garcia. Os diversos artigos encontrados no site oficial da AbpP (Associação Brasileira de Psicopedagogia) apontam ou pelo menos sugerem como uma das causas recorrentes das dificuldades de aprendizagem, no Brasil, a educação primária negligente, ou a alfabetização precária, ou ainda letramento inicial inoperante.

Os fatores psicomotores e sensoriais podem ser sinais ou indícios de dislexia, pelos quais o professor regular pode fazer o encaminhamento ao psicopedagogo, mas também são descartados por Garcia como causas da dificuldade de aprendizagem da leitura. $\mathrm{O}$ fato é que a motricidade geral, a orientação direita-esquerda, a percepção temporal, a organização perceptiva, o esquema corporal e a lateralidade são sinais de algum transtorno de aprendizagem relacionado à leitura.

Não é seguro afirmar que esses sinais constituem a causa da dislexia, mas que podem fazer parte da heterogeneidade de características relacionadas a algum transtorno da leitura ou mesmo da dislexia. Isso, contudo, deve ser observado pelo professor como um sinal de alerta de que algo não está bem com o sujeito aprendente e assim encaminhá-lo para observação, avaliação e diagnóstico psicopedagógico.

Garcia (1998, p. 175) afirma que esses fatores foram, curiosamente, "os predominantes nos programas de intervenção mais popularizados, e que continuam sendo utilizados 'para qualquer dificuldade de aprendizagem da leitura'”, asseverando posteriormente que existem vários tipos de DA de leitura ou mesmo vários tipos de dislexia. A Espanha é o exemplo claro dessa realidade.

Quanto aos fatores óculo-motores, há consenso em não itiga ra-los como origem da dislexia, visto que vai de encontro à definição de DA supramencionada. $\mathrm{O}$ cerco se fecha sobre a cognição propriamente dita, ou seja, os problemas de aprendizagem têm o cerne nas causas cognitivas, principalmente em relação à leitura. 
Sabe-se que a aprendizagem dos movimentos oculares é cultural, conforme o texto deva ser lido da esquerda para a direita ou vice-versa. Assim, é possível notar no disléxico o que S. Borel-Maisonny (1984, p. 62) chama de "movimento anárquico do olhar”, isto é, movimento sem foco progressivo e ordenado para a realização da leitura.

A literatura sobre a experiência psicopedagógica clínica atesta que os aprendentes que manifestam esse sinal óculo-motor anárquico também estabelecem de maneira extremamente difícil o agrupamento das letras expressivas de uma grafia, como se não conseguissem organizar o espaço a ser lido ou lembrar-se desta organização estabelecida no momento anterior, ou fazendo-o mediante trabalhoso enigma. Logo, soma-se ao quadro da dislexia a disortografia.

O autor citado acima apresenta em seu texto outros sinais de possível dislexia que os próprios professores de Língua Portuguesa e os pedagogos regentes podem observar para fazerem os devidos encaminhamentos. Resumidamente, são eles: a) confusão no reconhecimento dos grafemas $n, u, d, b, p, q$ ou dos fonemas a eles relacionados; b) falta de precisão na apreciação dos tamanhos da escrita (script); c) confusão dos caracteres perecidos $l$ $i, t f, a d, m c h, u v, o a$; d) habitual e persistente falta de discriminação na situação de umas letras em relação a outras: em me, ит ти, ао oa etc.; e) dificuldade sempre igual em decifrar uma mesma palavra, como se o esforço anterior não tivesse contribuído com nenhuma facilidade amnésica; f) dificuldade considerável na translineação leitora, fazendo-o com ocultamento de palavras ou segmentos e sempre usando o dedo para recuperar o foco; g) verdadeira "inaptidão" para associar a lembrança de um som com a imagem desse som representada por letras agrupadas ou inclusive isoladas (problema na relação significantesignificado-signo ou símbolo-referência-referente, como já explicou a Linguística pelas palavras de Saussure e pelo famoso triângulo de Ogden e Richards).

Garcia (1998) é mais objetivo e utiliza critérios de avaliação pedagógica geral para o diagnóstico do que ele chama de transtorno do desenvolvimento da leitura. São eles:

\footnotetext{
a) baixo rendimento nas provas padronizadas de leitura - tomando por pressuposto que a criança tenha passado por uma prova de inteligência administrada de forma individual, consoante a sua escolarização; b) alteração significativa nas aprendizagens acadêmicas ou nas atividades da vida cotidiana que requerem a habilidade de ler; c) não se considera a relação entre as alterações anteriores e defeitos de acuidade visual ou auditiva, nem a qualquer transtorno neurológico; d) a alteração b é decorrente de a. (p. 173-174)
} 
É importante considerar as fases do desenvolvimento cognitivo e a relação destas com a aprendizagem. Piaget exemplificou a contento através da experiência com conservação de quantidades que a operação de pensamento chamada reversibilidade não está maturada em crianças com menos de sete anos de idade, que ainda pensam por justaposição. Elas não entendem que uma quantidade $\mathbf{x}$ colocada em recipiente diferente permanece a quantidade $\mathbf{x}$. Não obstante, os adultos entendem.

Não é uma simples questão de ensinar a criança tal raciocínio para que ela resolva a situação-problema. O fato é que ela ainda não compartilha do mesmo ponto de vista do adulto porque não possui as características do pensamento lógico-operacional que evidenciam a conservação. Esse nível de desenvolvimento cognitivo não foi superado. ${ }^{2}$

A respeito do desenvolvimento da inteligência, Vygotsky (1973) considera elemento importante a maturação biológica, mas dá mais ênfase ao papel da história social e cultural na aprendizagem e na inteligência. Para ele, a mediação simbólica da linguagem, e hoje das linguagens virtuais icônicas da internet - grifo nosso -, fazem diferença na aquisição do conhecimento, e a mediação correta do professor ou de alguém mais experiente pode ser determinante no processo de aprendizagem.

De qualquer maneira, entende-se que crianças na referida faixa etária não podem ser avaliadas e diagnosticadas como portadoras de distúrbios de aprendizagem simplesmente porque responderam negativamente às perguntas do teste piagetiano de conservação de quantidades, sabendo que elas não têm a devida maturidade cognitiva para tal.

Bossa (1994, p. 5-22) corrobora a argumentação acima, defendendo que

O trabalho do psicopedagogo tem caráter multifacetado, visto que engloba o trinômio escola-sociedade-família. As relações entre a conjuntura social em que está a família e a estrutura sistemática do trabalho escolar estão no cerne das pesquisas e intervenções psicopedagógicas. Interessa mais ao especialista entender a interferência dessas relações na aprendizagem do que simplesmente avaliar e classificar etiologicamente um distúrbio ${ }^{3}$ de aprendizagem. Seu trabalho tem dimensões além da abordagem clínica.

\footnotetext{
${ }^{2}$ A respeito uso dos exames e testes de Piaget é válido consultar "O método clínico usando os exames de Piaget" (1994), de Terezinha Nunes Carraher.

${ }^{3}$ Mais adiante, no capítulo que aborda o problema - o objeto de investigação - serão explorados alguns meandros da nomenclatura técnica da psicopedagogia referentes às diferenças entre problema, dificuldade, transtorno e distúrbio de aprendizagem. 
Id on Line Revista Multidisciplinar e de Psicologia

Id on Line Multidisciplinary Journal and Psycology

\section{A evolução do conceito de dislexia}

Para Zunino e Pizani, (1995) o conceito de dislexia foi introduzido por Ranschburg em 1916. A palavra, cujo original é "legasthenie", designava a incapacidade devido a lesão central do sistema nervoso para ler compreensivelmente, isto é, uma deficiência parcial da inteligência, podendo ocorrer também em caso de deficiência geral da inteligência.

Os autores também revelam outros tipos de dislexias: a dislexia isolada, que ocorre com alunos cuja inteligência é boa e até acima do normal; e a dislexia geral, dificuldade de leitura e escrita associada à deficiência escolar geral que ocorre com alunos com uma inteligência abaixo da média.

A este último tipo de dislexia chama-se de dislexia do meio, cujas causas são as condições ambientais e socioculturais desfavoráveis, observadas facilmente na realidade social e escolar brasileira.

Esses e outros autores estão no grupo que apontam para aspectos parciais que são não mais que fatores causadores, como a "deficiência de estruturação das formas", a "deficiência de interpretação" e a "deficiência de memória". É fácil hoje encontrar, em sites especializados ou em formatos impressos, informações pormenorizadas sobre testes para diagnosticar a dislexia. No entanto, é preciso interpretar, à luz de teorias vigentes, tanto a natureza dos testes quanto seus possíveis resultados.

Piaget, hoje uma forte referência para a educação escolar também apresentou, em pesquisa de décadas atrás, seu conceito. Na opinião de Bouton (1974, p. 399), ele defende que a hipótese mais forte para a etiologia da dislexia é a maturação atrasada do desenvolvimento cerebral e descarta perturbações emocionais como causadoras do problema, embora estas possam complicar a situação da criança e contribuir para revelar o déficit, além de constituir um comportamento de defesa.

Atualmente, a mais coerente concepção de dislexia é aquela que a considera uma síndrome, ou seja, a quantidade e a relação entre múltiplos fatores que agem no cerne da cognição. Vale salientar que grupos de pesquisadores se dividem quanto a considerar os fatores afetivo-emocionais na origem do problema como um transtorno influente na aprendizagem ou como dislexia propriamente dita. 
Id on Line Revista Multidisciplinar e de Psicologia

Id on Line Multidisciplinary Journal and Psycology

\section{Resultados}

Diante do exposto, cabe ao professor regular realizar com alta proficiência a etapa de prevenção primária mediante a mudança do enfoque teórico, o replanejamento das ações didáticas e metodológicas e o desenvolvimento de uma proposta pedagógica diferenciada para o contexto dos estudantes aprendentes, que leve em conta as singularidades dos sujeitos em fase de aprendizagem.

Bossa (1994, p. 78-85) resume o ideário acima asseverando que

a proposta pedagógica deve ter objetivos gerais e específicos claros e bem definidos e organizar o uso real e profícuo dos recursos materiais disponíveis na escola em atividades diversas rigorosamente planejadas a fim de evitar o aparecimento ou agravamento de problemas de aprendizagem, até mesmo mitigá-los.

Viu-se que a ciências cognitivas têm forte influência na abordagem dos problemas de aprendizagem: paradigmas de funcionamento cognitivo imperam nas considerações e conclusões a respeito desses problemas. Propõe-se, então, com base na análise de conteúdo bibliográfico resumida neste artigo, que pesquisas sejam feitas no sentido de expandir a perspectiva e o horizonte para o nível maior de análise do que este que vem sendo abordado.

Pesquisas em Linguística e Pedagogia, e também nas Ciências Humanas e Sociais vêm demonstrando, nos últimos anos, apesar das diferenças de seus escopos de pesquisa e abordagem, a mudança paradigmática na dinâmica social do conhecimento, a qual se fortalece com as novas tecnologias de informação e comunicação. Estas, por sua vez, interferem no desenvolvimento da inteligência, com novos estímulos e novas demandas de equilibração para usar um conceito piagetiano -, nas formas de relações sociais e na articulação política, além de influenciar na construção e divulgação do conhecimento científico.

Olhares sob outros prismas devem ser considerados porque trazem elucidação a respeito de questões que interferem direta ou indiretamente no tema tratado neste artigo. Diretamente relacionados ao tema deste artigo são temas como a ressignificação da visão sistêmica do conhecimento, proposta por Morin (2003); os conceitos de ciberespaço, cibercultura e cibereducação propostos por Lévy (1999), relacionados a novas rotinas neuromotoras interferentes no ato de aprender, não apenas no aspecto cognitivo endógeno, mas também no aspecto exógeno. 
Isso significa que rotinas mentais relacionadas às mudanças culturais decorrentes da nova ordem socioeconômica do capitalismo globalizante mudam os processos sociais e influenciam o comportamento - o papel da história cultural no desenvolvimento da inteligência ou psicogênese já foi salientado por Vygotsky (1973) e sua base teórica é componente dos Parâmetros Curriculares Nacionais.

É também notável o conceito de cidade educativa proposto por Cortesão e Stoer (2002); a renovação da Didática crítica, com a (re)incorporação de outros temas no arcabouço teórico, como a influência do paradigma Toyota nos sistemas de ensino, tratado por Horta (2010); os estudos histórico-críticos acerca do modus operandi das políticas públicas no Brasil, mormente aquelas destinadas à educação - Bacelar (2003); a proposta de reestruturação dos programas de formação acadêmica inicial e continuada (PIMENTA, 1996). Esses estão em destaque, dentre outros também importantes.

O arcabouço teórico acima deve cooperar para a ressignificação das práticas avaliativas, diagnósticas, interventivas, pedagógicas e gestoras, incluindo os professores que lidam diretamente com os estudantes e os profissionais de apoio: psicopedagogos, psicólogos, assistentes sociais e gestão escolar.

\section{Considerações finais}

A despeito das mudanças de perfil de professor e estudante nas últimas décadas, a educação escolar continuará com valor significativo na sociedade, caso passe a considerar as potencialidades e singularidades dos sujeitos no processo de ensino-aprendizagem. Nesse contexto, conhecimentos psicopedagógicos são valiosos para garantir o respeito ao sujeito em formação.

A argumentação expôs que tipos específicos de dislexia causados por lesões cerebrais ou fatores genéticos e neurológicos existem, mas aumentam os casos de dislexia relacionados a fatores afetivos, emocionais, sociais e pedagógicos, sendo estes últimos o foco da etiologia na abordagem psicopedagógica em questão nesse trabalho.

Logo, faz-se necessária a interlocução da psicopedagogia com outras ciências, dentro de uma visão sistêmica, pois há relações intercambiantes entre essa área de estudo com outros conhecimentos sobre o ato de aprender e ensinar. 
Portanto, a relação entre cognição social e postura político-pedagógica da escola e do professor, e as implicações dessas relações no sujeito aprendente precisam ser consideradas quando os propósitos maiores são superar o paradigma homogeneizador da escola brasileira, realçar as potencialidades dos sujeitos e alcançar a qualidade da educação.

\section{Referências}

AJURIAGUERRA, J. (Org.). A dislexia em questão: dificuldades e fracassos na aprendizagem da língua escrita. Porto Alegre: Artes Médicas, 1984.

BACELAR, Tânia. "As políticas públicas no Brasil: heranças, tendências e desafios". In: SANTOS JÚNIOR, Orlando Alves dos [et. al.]. Políticas Públicas e Gestão Local: programa interdisciplinar de capacitação de conselheiros municipais. Rio de Janeiro: FASE, 2003.

BOREL-MAISONNY, S. "Resposta de S. Borel-Maisonny". In AJURIAGUERRA, J. (Org.). A dislexia em questão: dificuldades e fracassos na aprendizagem da língua escrita. Porto Alegre: Artes Médicas, 1984.

BOSSA, Nadia Aparecida. A psicopedagogia no Brasil: contribuições a partir da prática. Porto Alegre: Artes Médicas, 1994.

BOUTON, C.P. O desenvolvimento da linguagem. Lisboa, Portugal: Moraes Editora, 1974.

CARRAHER, Terezinha Nunes. O método clínico: usando os exames de Piaget. São Paulo: Cortez, 1994.

CORTESÃO, Luiza; STOER, Stephen R. "Cartografando a transnacionalização do campo educativo”. In SANTOS, Boaventura de Sousa (org.). A Globalização e as Ciências Sociais. São Paulo: Cortez Editora, 2002.

GARCIA, Jesus Nicasio. Manual de dificuldades de aprendizagem: linguagem, leitura, escrita e matemática. Porto Alegre: Artes Médicas, 1998.

HORTA, Rosilene. "A Didática crítica frente ao toyotismo e às tecnologias informacionais". In TEIXEIRA, Adla Betsaida Martins (org.). Temas atuais em Didática. Belo Horizonte, MG: Editora UFMG, 2010.

LÉVY, Pierre. Cibercultura. São Paulo: Editora 34, 1999.

MORIN, Edgar. A cabeça bem feita: repensar a reforma, reformar o pensamento. Rio de Janeiro: Bertrand Brasil, 2003. 
OLIVEIRA, Sílvia Suely Sillos de. A importância do psicopedagogo frente às dificuldades de aprendizagem. .Net. Disponível em: <http://www.psiopedagogia.com.br.htm>.Acesso em novembro de 2010.

PIMENTA, Selma Garrido. Formação de professores - saberes da docência e identidade do professor. Revista da Faculdade de Educação da Universidade de São Paulo, v.22, n.2, p. 7289, jul. / dez. 1996.

VIGOTSKY, L. Pensamiento y lenguaje. Buenos Aires, La Pléyade, 1973.

ZUNINO, Delia Lerner de; PIZANI, Alicia Palacios de. A Aprendizagem da Língua Escrita na Escola: reflexões sobre a proposta pedagógica construtivista. Porto Alegre: Artes Médicas, 1995.

\section{Como citar este artigo (Formato ABNT):}

AMORIM, E.B.O.S.; OLIVEIRA, G.F. Dislexia em Perspectiva: Contribuições da Psicopedagogia e da psicologia. Id on Line Revista Multidisciplinar e de Psicologia, Set-Out de 2016, vol.10, n.31, Supl 2, p. 135-146. ISSN 1981-1179.

Recebido: 06/09/2016

Aceito: 12/09/2016 